\title{
Experiences of Intersecting Inequalities for Christian Women and Girls in Pakistan
}

In Pakistan, where gender-based discrimination is already rampant, women and girls belonging to religious minority or belief communities face multiple and intersecting forms of discrimination over and above those faced by an average Pakistani woman and girl. This policy briefing shares findings from a study on the situation of socioeconomically excluded Christian women and girls in Pakistan. During the research, they discussed their experiences of different forms of discrimination, which predominantly took place within their workplace (largely sanitary, domestic and factory work) and educational institutes, particularly in government schools. They described being restricted in their mobility by their families and communities who are fearful of the threats of forced conversion, and both poor and affluent women relayed experiences of harassment at healthcare and education facilities once their religious identity is revealed.

\section{Key messages}

- Religious discrimination primarily took place within the workplace and educational institutes and affects both poor and affluent Christian women.

- Sexual harassment is a significant threat, with abduction, forced conversion to Islam, underage and forced marriage, statutory rape as the predominant form of violence facing Christian women, particularly minor girls from poor strata of the community/society.

- The reality of domestic violence in the lives of Christian women and girls, however, shows that the discrimination and marginalisation they face is not only from the wider, external community, but also present within their own community.

\section{Context}

Pakistan's Constitution includes de jure obligation to ensure non-discrimination and equality among its citizens, as enshrined in Articles 20 and 25 which respectively guarantee freedom of religion and equality among citizens. Pakistan is also a state party to several international human rights instruments, such as the International Convention on the Elimination of All Forms of Racial Discrimination (CERD) and the Convention on the Elimination of all Forms of Discrimination Against Women (CEDAW), which prohibit any form of discrimination, including on the basis of gender and religion or belief. Nonetheless, discrimination against religious minorities is prevalent in the country and ranges from discriminatory laws and policies to

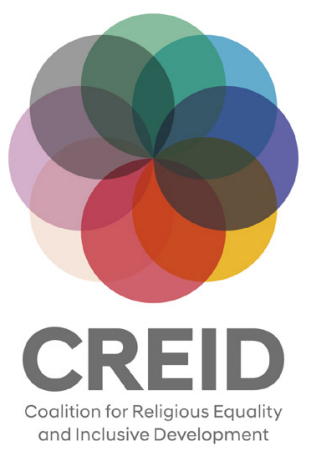


a religiously biased mindset at societal level and Pakistani religious minorities are faced with discrimination and faith-based violence. Based on the latest available figures, Pakistan's religious demography is 96.28 per cent Muslims and 3.72 per cent religious minorities including Christians, Hindus, Ahmadis, Scheduled Castes and others (Sikhs, Parsis, Bhais, and so forth).

The population of religious minority women in Pakistan is estimated to be around 3 million, of which approximately 90 per cent reside in Sindh and Punjab and 92 per cent belong to Hindu, Christian and Scheduled Caste communities. Most of these women work in both the formal and informal labour sectors, such as in agriculture, sanitation, the brick-kiln industry, and as domestic workers. While gender-based discrimination is rampant in Pakistan, women and girls belonging to religious minority or belief communities face multiple and intersecting forms of discrimination in addition to those faced by an average Pakistani woman and/or girl, such as:

- being a woman in a patriarchal society;

"Gender-based discrimination against religious minority women and girls ranges from social exclusion in daily life and different forms of harassment to abduction, statutory rape, forced conversion, and forced marriage"

- coming from religious minority communities in a religiously biased society;

- socioeconomic marginalisation;

- discriminatory laws and policies.

Gender-based discrimination against religious minority women and girls ranges from social exclusion in daily life and different forms of harassment to abduction, statutory rape, forced conversion, and forced marriage.

\section{Methodology Note \\ Focus Group Discussions using participatory ranking}

The research was carried out through eight focus group discussions (FGDs) held in July 2020. Participants were residents of Yuhannabad - Lahore, said to be the largest Christian community settlement in Pakistan, and belonged to the lower social classes, working as domestic, factory and sanitation workers. Six FGDs were held with Christian women and girls (divided in three age groups - 15-20 years, $21-30$ years and $31-50$ years) and two with Christian men (who ranged from 20-50 years) from the same communities. Altogether, 36 women and girls and 12 men took part. Participatory ranking, in which participants identified and ranked what they perceived to be the greatest threats in scale and depth facing poor Christian women and girls was used to generate quantitative data which was then expanded on by the generation of qualitative data collected during the discussions that followed. In addition to the FGDs, seven interviews were carried out with affluent Christian women to enable a comparison of discrimination and marginalisation from a class perspective.

The ranking process and focus groups were led by a researcher who is herself a Christian woman living in Pakistan and who has experienced similar discrimination and exclusion. This enabled her to connect well with the participants and explain the research questions in a way that she knew they would understand. 


\section{Key findings}

As the quantitative data was disaggregated by gender, two lists of the top five threats facing economically excluded Christian women and girls were generated. The Christian women and girls ranked the threats in the following way:

1. religious discrimination, particularly in educational institutes and the workplace,

2. sexual harassment,

3. lack of education,

4. unemployment, and

5. domestic violence.

Conversely, the Christian men gave the following ranking:

1. religious discrimination, particularly in educational institutes and the workplace,

2. sexual harassment,

3. unemployment,

4. lack of education, and

5. delay in receiving their salary.

It is significant yet perhaps unsurprising that Christian men did not rank domestic violence in the top five threats they believe Christian women and girls face, as this would implicate themselves as perpetrators of this gender-based discrimination. The reality of domestic violence in the lives of Christian women and girls demonstrates how the gender discrimination and marginalisation they face is not only from the wider, external community, but also present within their own community. This is one of ways in which economically excluded Christian women and girls face exclusion and marginalisation that Christian men from the same class and communities don't.

Religious discrimination was described as predominantly taking place within the workplace and educational institutes, particularly in government schools. Examples were given by the women and girls, such as employers not allowing Christian women to use the same utensils as the family and school teachers giving less attention to Christian girls, as well as scolding them for minor tasks that the Muslim students were not punished for.

While sexual harassment was ranked as the second threat, the ensuing discussion focused more on forced conversion to Islam as the predominant form of violence facing Christian women and girls. In fact, 97 per cent of the women and girls who participated in the focus groups reported that invitations to convert to Islam had become a regular part of their life that they had no choice but to deal with. All participants described how they felt that the police would not be supportive of Christian women and girls if a case of violence against them was reported.

Finally, the interviews with the affluent Christian women revealed very similar instances of harassment and discrimination to those described by the economically excluded Christian women and girls. 
For example, affluent Christian women described also having to adopt the dress codes and habits of the Muslim women from the majority to avoid the harassment that comes with being identified as non-Muslim. Additionally, while these women had better job options than the economically excluded women, such as working for non-governmental organisations (NGOs), they also faced stigmatisation by the society such as being accused of trying to spread a foreign agenda while running workshops on gender equality because of their Christian identity. They also emphasised forced conversion and forced marriage as very real threats being faced on a regular basis specially by the religious minority minor girls from the poor section of the community.

\section{Policy recommendations}

Based on these research findings, the following policy recommendations are made to tackle the intersecting inequalities and marginalisation facing Christian women and girls in Pakistan:

- Governmental and non-governmental sections should initiate programmes for the socioeconomic empowerment of Christian/ minority women.

- Government and private sector should involve Christian/minority women in decision-making through their inclusion as staff members in key positions and beneficiaries of different programmes.

- Robust safeguards should be introduced and implemented in all workplaces in order to protect Christian/minority women from every kind of exploitation. Moreover, implementation of the Protection against Sexual Harassment at Workplace Act 2010 should be prioritised.

- Robust legal and judicial safeguards should be enforced against forced conversions, marriages and the related crimes of abduction and rape of women and girls belonging to religious minorities.

- The current Commission for Minorities is not a statutory body, therefore an independent, autonomous and permanent Commission(s) for Minorities must be set up. This must be provided with adequate human and financial resources constituted at Federal and Provincial level, with the powers of a tribunal, to examine complaints and ensure a timely redress.

- Current Family or Personal laws for religious minorities in Pakistan should be reviewed by a competent body to check injustices against minority citizens, particularly minority women, and to ensure that these laws comply with human rights standards and prevent the overriding effect of the personal law of the majority (Muslim) community. Moreover, family laws should be enacted for Sikh, Kalash and other minority communities that provide for a marriage registration/certificate and other important safeguards and arrangements for fulfilment of human rights.

- The curriculum for schools, colleges and universities should be revised to eliminate existing hate speech against religious minorities and must include their role in the progress of Pakistan.
"[F]orced

conversion and

forced marriage

as very real

threats being

faced on a regular

basis" 
- The Federal and Provincial Governments should ensure comprehensive implementation of the 5 per cent job quota for minorities and an equivalent quota ( 5 per cent) should be introduced at all government educational and technical training institutions. Within this quota, there must be specific provision made for minority women who are often excluded from both the quotas for minorities and from the quotas for women.

\section{Further reading}

Adnan, R. (2020) 'We Ran Out of Options; Coronavirus Wreaks Havoc on Low-wage Christian Workers', Ravadar, 11 September

Suleman, N. (2020) 'A Case of Several Jeopardies: A Study on the Intersecting Inequalities in the Everyday Lives of Poor Minority Christian Women and Girls' in M. Tadros (ed.) Violence and Discrimination against Women of Religious Minority Backgrounds in Pakistan, CREID Intersection Series: Gender and Religious Inequalities, Brighton: Institute of Development Studies, DOI: 10.19088/CREID.2020.003

Suleman, N. (author) and Buchanan, E. (presenter) (2020) Naumana Suleman on Empowering Women from Religious Minorities in Pakistan, CREID Podcast, 3 September

Tadros, M. (ed.) (2020) Violence and Discrimination against Women of Religious Minority Backgrounds in Pakistan, CREID Intersection Series: Gender and Religious Inequalities, Brighton: Institute of Development Studies, DOI: 10.19088/CREID.2020.003

\section{Credits}

This policy brief draws on the CREID paper 'A Case of Several Jeopardies: A Study on the Intersecting Inequalities in the Everyday Lives of Poor Minority Christian Women and Girls' by Naumana Suleman. It was compiled by Amy Quinn-Graham and edited by Emilie Wilson. It was produced as part of the Coalition for Religious Equality and Inclusive Development (CREID), a consortium funded by UK Aid from the UK government which provides research evidence and delivers practical programmes which aim to redress the impact of discrimination on the grounds of religion or belief, tackle poverty and exclusion, and promote people's wellbeing and empowerment.

The opinions expressed are those of the author and do not necessarily reflect the views or policies of IDS or the UK government.

CREID Policy Briefings are published by the Institute of Development Studies and aim to share key research findings and make practical recommendations for policymakers and donors.

(cc) BY This is an Open Access publication distributed under the terms of the Creative Commons Attribution 4.0 International licence (CC BY), which permits unrestricted use, distribution, and reproduction in any medium, provided the original authors and source are credited and any modifications or adaptations are indicated.

\section{DOI: 10.19088/CREID.2020.013}
